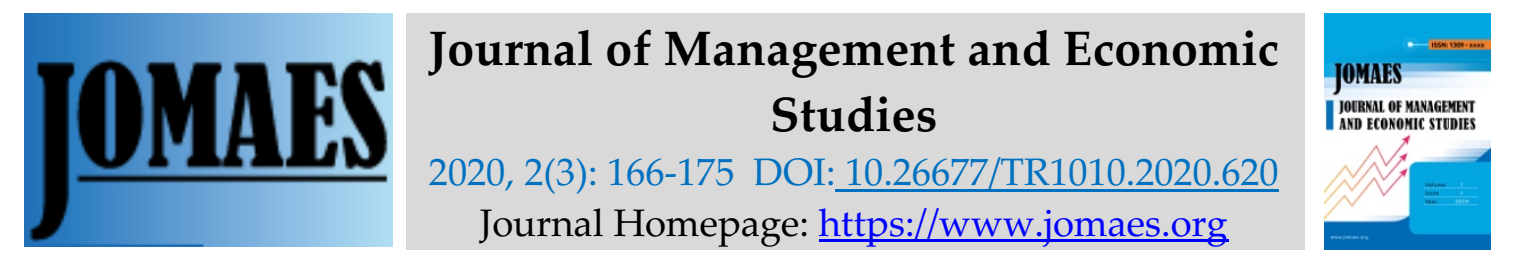

\title{
The Effects of Internal Control Problems and Tolerance for Ambiguity on Lending Judgments ${ }^{1}$
}

\author{
Arnold SCHNEIDER \\ Scheller College of Business, 800 W. Peachtree St., Georgia Institute of Technology, \\ Atlanta, GA 30308 USA \\ aschneider@gatech.edu
}

\begin{abstract}
Purpose: This research examines whether lenders' judgments are more adversely impacted by disclosures of material weaknesses versus significant deficiencies in a borrower's internal controls. This study also examines whether lenders' tolerance for ambiguity affects lending judgments.

Methodology: An experiment was conducted with lending officers, who provided risk assessments and lending probabilities for a hypothetical loan applicant company. One independent variable, the company's internal controls, was manipulated using two levels material weaknesses versus significant deficiencies. The other independent variable, tolerance for ambiguity, was measured with a commonly used scale for this attribute.

Major Conclusions: The severity of internal control problems had no effect on either risk assessments or probabilities of granting a line of credit. In addition, tolerance for ambiguity did not affect risk assessments, but lenders with a high tolerance for ambiguity had an average credit granting probability that was lower than lenders with a low tolerance for ambiguity.
\end{abstract}

Keywords: internal controls; commercial lending; tolerance for ambiguity.

\footnotetext{
${ }^{1} \mathrm{I}$ am grateful for the research assistance and comments provided by Suyun $\mathrm{Wu}$.
} 


\section{Introduction}

The Sarbanes-Oxley Act of 2002 requires that publicly traded companies report on the effectiveness of their internal controls over financial reporting. In addition, the companies' auditors must provide an opinion on the effectiveness of these internal controls. A material weakness occurs when a control deficiency or combination of deficiencies exist such that there is a reasonable possiblility that a material misstatement of the financial statements could result. A material weakness must be disclosed, and for companies with a public float of $\$ 75$ million or more, this necessitates the reporting of an adverse internal control opinion by the company's auditor. Companies may also choose to voluntarily disclose siginficant deficiencies, which are internal control deficiencies that are less severe than material weaknesses, but have more than a remote likelihood that a misstatement in financial statements that is more than inconsequential could result. Hammersley, Myers, and Shakespeare (2008) report that over 24 percent of their sample of firms reporting control deficiencies disclosed a significant deficiency. Clean (i.e., unqualified) internal control opinions would still be given by auditors when significant deficiencies are disclosed.

Commercial lenders are an important user group that relies on audited financial statements, as well as on disclosures and audit opinions involving internal controls. Previous research studies (e.g., Schneider and Church, 2008; Kim, Song, and Zhang, 2011) have found that lending decisions are adversely impacted by loan applicants' disclosures of material weaknesses in internal controls as compared to effective internal controls. This research extends the focus of prior studies by examining lending decisions in the context of material weakness disclosures versus significant deficiency disclosures. That is, are lenders' judgments more adversely impacted by disclosures of material weaknesses than by disclosures of significant deficiencies?

Another issue addressed is whether lenders' tolerance for ambiguity affects these lending decisions. Tolerance for ambiguity is a personality trait that measures the extent to which one feels threatened by ambiguous information or ambiguous situations (Dermer, 1973). Ambiguity can take on the following meanings: vague, incomplete, or fragmented information; uncertainty in terms of the state of the mind; inconsistencies, contradictions, and contraries; unclear stimuli; a stimulus with multiple meanings (Norton, 1975). Someone with low tolerance for ambiguity experiences stress, reacts prematurely, and avoids ambiguous stimuli, while those with high tolerance for ambiguity perceive ambiguous stimuli/situations as desirable, challenging, and interesting (Furnham and Ribchester, 1995).

The terms "material weakness" and "significant deficiency" could be viewed as ambiguous. Whereas a material weakness suggests there is a reasonable possibility that a material misstatement of the financial statements could result, a significant deficiency denotes more than a remote likelihood that a misstatement in financial statements that is more than inconsequential could result. The phrases "reasonable possibility" and "more than a remote likelihood" could be ambiguous. Moreover, the phrases "material misstatement" and "misstatement that is more than inconsequential" could be ambiguous. This study examines whether lenders who have a low tolerance for ambiguity make lending judgments that differ from lenders who have a high tolerance for ambiguity.

\section{Prior Research}

\section{Internal Control Disclosures}

Internal control disclosures have been addressed in numerous studies. Most of these studies focus only on material weakness disclosures (e.g., Jiang, Rupley, and $\mathrm{Wu}, 2010 ; \mathrm{Li}, \mathrm{Yu}, \mathrm{Zhang}$, and Zheng, 2016). Several studies have included both material weakness disclosures as well as 
disclosures of non-material internal control deficiencies. Hogan and Wilkins (2008) show that audit fees are much higher when material weaknesses are disclosed than when significant deficiencies are disclosed, suggesting that auditors increase their audit effort in the presence of increased control risk. Hammersley, Myers, and Shakespeare (2008) find that stock market returns are more negative when firms report material weaknesses than when they report control deficiencies and when firms report significant deficiencies rather than control deficiencies. Kim and Park (2009) demonstrate that when firms disclose internal control deficiencies, their abnormal stock returns are negatively associated with changes in the standard deviation of daily stock returns. This suggests that when disclosures of internal control deficiencies reduce uncertainty in the market, they have a less negative impact on stock prices. Furthermore, the impact of the uncertainty reduction is greater for voluntary disclosures of non-material control deficiencies. Results of an experiment by Church and Schneider (2016) reveal that participants react negatively to material weakness disclosures by investing less in those companies, but they do not react negatively to significant deficiency disclosures.

Several studies have examined internal control deficiencies in the context of lending decisions and costs of debt. Kim, Song, and Zhang (2011) find that bank loan spreads are higher for companies that disclose material internal control weaknesses. Moreover, companies with more severe, company-level material weaknesses incur higher loan rates than those with less severe, account-level material weaknesses. Consistent with these results, Dhaliwal, Hogan, Trezevant, and Wilkins (2011) also show that a company's credit spread on its publicly traded debt marginally increases if it discloses a material weakness. Costello and Wittenberg-Moerman (2011) demonstrate that when a company reports a material internal control weakness, lenders reduce their use of financial covenants and financial-ratio-based performance pricing provisions and substitute them with other measures such as price and security protections or credit-rating-based performance pricing provisions. Schneider and Church (2008) find that lenders' assessments of the risk of extending a line of credit as well as the probability of granting the line of credit are negatively affected when the company has material internal control weaknesses accompanied by an adverse internal control audit opinion as compared to no material internal control weaknesses accompanied by an unqualified opinion. All of these studies involve internal control deficiencies that are characterized as material weaknesses. The current study compares the effects on lending decisions of material weaknesses disclosures to disclosures of significant deficiencies.

Tolerance for Ambiguity

Tolerance for ambiguity is a personality trait that has been studied in a number of accounting contexts. Studies by McGhee, Shields, and Birnberg (1978), Oliver and Flamholtz (1978), Gul (1984), Faircloth and Ricchiute (1981), and Weisbrod (2009) have examined tolerance for ambiguity in settings involving investing and financial reporting. Pincus (1990), Vaassen, Baker and Hayes (1993), and Wright and Davidson (2000) have addressed tolerance for ambiguity in the context of auditing issues, while Chong (1998) used a management accounting setting to investigate tolerance for ambiguity.

Two studies have addressed tolerance for ambiguity in the context of lending decisions. Gul (1986) finds that when the audit opinions are qualified, lenders with a low tolerance for ambiguity are less confident than lenders with a high tolerance for ambiguity. However, when audit opinions are unqualified, there is no difference in levels of confidence. Tsui (1993) examined "subject to" audit qualifications due to uncertainty about pending litigation. Findings indicate that lenders with a low tolerance for ambiguity require higher interest rate premiums than lenders with a high tolerance for ambiguity. 


\section{Hypotheses}

Because material weaknesses in internal controls are more serious than significant deficiencies, the following hypotheses posit more adverse consequences associated with material weakness disclosures than for significant deficiency disclosures:

H1a: Risk assessments will be higher for companies that disclose a material weakness in internal controls as compared to companies that disclose a significant deficiency in internal controls.

$H_{1 b}$ : Probabilities of granting lines of credit will be lower for companies that disclose a material weakness in internal controls as compared to companies that disclose a significant deficiency in internal controls.

Both material weakness and significant deficiency disclosures convey some degree of ambiguity because they are defined by the terms "reasonable possibility", "more than a remote likelihood", "material misstatement", and "misstatement that is more than inconsequential." Therefore, lenders who have a low tolerance for ambiguity might be expected to react more negatively in lending scenarios involving material weakness or significant deficiency disclosures than do lenders who have a high tolerance for ambiguity. This would suggest a lower tolerance for ambiguity would imply higher risk assessments, and in turn, lower probabilities of granting credit. Prior psychology research has indeed found evidence that low tolerance for ambiguity is associated with risk aversion (Furnham and Marks, 2013). Hence, the following hypotheses are presented:

$H_{2 a}$ : Risk assessments will be higher for lenders having a low tolerance for ambiguity as compared to lenders having a high tolerance for ambiguity.

$H_{2 b}$ : Probabilities of granting lines of credit will be lower for lenders having a low tolerance for ambiguity as compared to lenders having a high tolerance for ambiguity.

\section{Methodology}

Particpants were assigned to one of two treatment groups, each of which described the same hypothetical company scenario except for its internal control disclosure. The scenario contained background information about the company and its financial statements for recent years. ${ }^{2}$ The scenario also indicated that the company's financial statements were audited by a national CPA firm and received a clean opinion. One treatment group was informed that the company had disclosed a material weakness in its internal controls and therefore received an adverse internal control opinion, while the other group was informed that the company had received a clean internal control opinion, but had disclosed a significant deficiency in its internal controls. A weakness/deficiency was chosen that could be viewed either as a material weakness or as a significant deficiency. The deficiency chosen was based on a case appearing in Earley, Hoffman, and Joe (2008), which included an internal control deficiency that was characterized as an atmargin case between a significant deficiency and a material weakness. ${ }^{3}$ Participants in both groups were informed that there was a lack of segregation of duties over the company's shipping and receiving and the inventory record-keeping functions.

\footnotetext{
2 The scenario is similar to the one used in a commercial lending study by Schneider (2018).

${ }^{3}$ Case 6 in Earley et al. (2008:1483).
} 
The lenders first assessed the level of risk, on a 10-point scale from very low risk to very high risk, associated with extending a five million dollar line of credit to the company. Next, they provided the probability that they would grant the five million dollar line of credit to the company at a reasonable rate of interest as determined by their financial institution. Afterwards, the lenders rated the importance of various factors in making their lending judgments. Finally, they responded to several demographic questions and then provided responses relating to the assessment of their tolearance for ambiguity, which was measured by using the AT-20 scale developed by MacDonald (1970). ${ }^{4}$ Consistent with prior research (e.g., Gul, 1984), a median split was conducted to categorize participants into two groups - high tolerance for ambiguity or low tolerance for ambiguity.

The combination of the two internal control treatment groups and the two tolerance for ambiguity groups yields the following four cells: Significant Deficiency/High Tolerance for Ambiguity (SDH), Significant Deficiency/Low Tolerance for Ambiguity (SD-L), Material Weakness/High Tolerance for Ambiguity (MW-H), and Material Weakness/Low Tolerance for Ambiguity (MWL).

\section{Participants}

Commercial lending officers in the southeastern portion of the U.S. were called by phone and asked whether they were willing to complete and/or distribute questionnaires for a study involving the effects of financial informaton on commercial lending decisions. If they agreed, then one or more questionnaires were mailed or emailed to them. A total of 70 commercial lending officers from 43 different banks completed the questionnaires. They average 23 years of experience as loan officers, have an average age of 52 years, and 93 percent are male. The distribution of participants into the four group cells created by the two internal control disclosure treatments and the two tolerance for ambiguity groups appears in Table 1. Statistical tests reveal no significant differences in demographics among the four cells.

Table 1. Mean Risk Assessments and Probabilities of Lending

\begin{tabular}{|c|c|c|}
\hline & Mean & Mean \\
\hline & Risk & Probability \\
\hline Group [sample size] & Assessment $^{*}$ & of Lending \\
\hline SD-H [n = 19] & 6.63 & 0.48 \\
\hline SD-L [n = 15] & 5.93 & 0.54 \\
\hline MW-H [n = 16] & 6.94 & 0.39 \\
\hline MW-L [n = 20] & 6.65 & 0.54 \\
\hline
\end{tabular}

\footnotetext{
${ }^{4}$ The AT-20 scale ranges from 1 to 20 . The median value for participants in this study is 7.25 and the range is 1 to 15 .
} 


\section{Results}

Overall, the average risk assessment (1=very low risk at all; $10=$ very risky) was 6.56 and ranged from 5.93 to 6.94 . The average probability of granting the line of credit was $49 \%$ and ranged from $39 \%$ to $54 \%$. The break-down of responses for each of the four cells is shown in Table 1 .

A $2 \times 2$ MANOVA reveals that the differences among risk assessments and probabilities of loan approval are not statistically significant across the two internal control groups (Wilks' Lambda $=$ $0.90 ; \mathrm{p}=0.36$ ) and also not statistically significant across the two levels of tolerance for ambiguity (Wilks' Lambda $=0.95 ; p=0.22$ ). Lenders in the significant deficiency treatment condition have a combined average risk assessment of 6.32 , while those in the material weakness treatment have a combined average risk assessment of 6.78. This result is in the expected direction as hypothesized in $\mathrm{H}_{1 \mathrm{a}}$, but the difference is not statistically significant $(\mathrm{p}=0.30)$, as shown in the ANOVA results found in Panel A of Table 2. Lenders in the significant deficiency treatment condition have a combined average credit granting probability of $50 \%$, while those in the material weakness treatment have a combined average credit granting probability of $47 \%$. Again, this result is in the expected direction as hypothesized in $\mathrm{H}_{1 \mathrm{~b}}$, but is not statistically significant $(\mathrm{p}=$ 0.49 ), as shown in Panel B of Table 2. Hence, there is not enough evidence to support any effect of the severity of internal control problems on either risk assessments or probabilities of granting lines of credit.

Table 2. ANOVA Results

Panel A: ANOVA with Risk Assessment as the Dependent Variable

\begin{tabular}{|l|c|c|l|}
\hline Effect & Mean Square & F-statistic & p-value* \\
\hline Internal Control Issue & 4.51 & 1.09 & 0.30 \\
\hline Tolerance for Ambiguity & 4.19 & 1.01 & 0.32 \\
\hline Interaction & 0.73 & 0.18 & 0.68 \\
\hline
\end{tabular}

Panel B: ANOVA with Probability of Granting Credit as the Dependent Variable

\begin{tabular}{|l|l|l|l|}
\hline Effect & Mean Square & F-statistic & p-value* \\
\hline Internal Control Issue & 0.03 & 0.49 & 0.49 \\
\hline Tolerance for Ambiguity & 0.20 & 3.05 & $0.09^{* *}$ \\
\hline Interaction & 0.04 & 0.64 & 0.43 \\
\hline
\end{tabular}

${ }^{*}$ P-values are two-tailed.

** Indicates significance at the 0.10 level.

Lenders with a high tolerance for ambiguity have a combined average risk assessment of 6.77, while those with a low tolerance for ambiguity have a combined average risk assessment of 6.34 . This result is not in the expected direction as hypothesized in $\mathrm{H}_{2 \mathrm{a}}$, but the difference is not statistically significant $(p=0.32)$, as shown in Panel A of Table 2. Lenders with a high tolerance for ambiguity have a combined average credit granting probability of $44 \%$, while those who have 
a low tolerance for ambiguity have a combined average credit granting probability of $54 \%$. This result is not in the expected direction as hypothesized in $\mathrm{H}_{2 \mathrm{~b}}$, and the difference is statistically significant at $\mathrm{p}=.09$, as shown in Panel B of Table 2.

After demographic information was elicited, participants provided ratings on the importance of seven factors in making their lending decisions ( 1 = no importance; 10 = very important), as shown in Table 3. The most important factors were the three financial statements -- balance sheet, statement of cash flows, and income statement, having ratings of 9.10,9.00, and 8.80, respectively. In fact, all ratings are above the scale midpoint of 5.5, and the differences from this scale midpoint are statistically significant for all seven factors. The presence or absence of an internal control deficiency, with an average rating of 8.21 , falls right in the middle of the importance ranking of the seven factors. Thus, it appears that disclosures of internal control problems matter to lenders, but the results of this study indicate that the severity of the problems do not affect lending judgments (i.e., lenders are not differentially impacted between significant deficiencies and material weaknesses).

Table 3. Factor Importance Ratings

FactorMean Rating

Balance sheet

Statement of cash flows

Income statement

Presence or absence of an internal control deficiency

Securing loan with receivables

Company growth

Rating scale: 1 = no importance; 10 = very important

\section{Discussion and Conclusion}

A previous study by Schneider and Church (2008) finds that the disclosure of an internal control problem by a loan applicant negatively affects commercial lending judgments. The current study extends Schneider and Church (2008) by examining whether the severity of a loan applicant's internal control problems adversely impacts lending decisions. Statistical tests did not provide support for the severity of internal control problems having an adverse effect on either risk assessments or probabilities of granting lines of credit. An implication of this finding is that while prospective borrowers would not want to report internal control problems, if they do report problems, they need not be more concerned that their internal controls are reported to have material weaknesses rather than significant deficiencies.

This study also finds that tolerance for ambiguity did not appear to affect risk assessments, but contrary to expectations, lenders with a high tolerance for ambiguity had an average credit granting probability that was lower than that of lenders with a low tolerance for ambiguity. One possible explanation is that tolerance for ambiguity has been found to be associated with more 
effective information processing. Individuals with low tolerance for ambiguity tend to look for information that supports their preconceptions, while those with high tolerance for ambiguity tend to seek out objective information that can potentially disconfirm their prior beliefs (Albrecht et al., 2018). So, lenders having a high tolerance for ambiguity may tend to process the information provided by loan applicants more carefully. This greater scrutinization may better enable them to detect anomalies, leading to a lower likelihood of lending. Another possible explanation for why lenders with a low tolerance for ambiguity are more likely to lend is that prior research has found that those who are intolerant of ambiguity tend to be overconfident in their judgments (Furnham and Marks, 2013). The overconfidence may lead to less careful analysis of the information provided by the borrower and, in turn, a lower chance of detecting anomalies that would question the advisability of granting the loan.

The usual limitations in experimental studies also pertain to this research. This study's findings relate to a particular loan setting and cannot necessarily be generalized to other loan settings. Future research should examine the effects of internal control problems and tolerance for ambiguity in loan settings having different characteristics involving the type of loan applicant, collateral, credit line amount, and financial condition of the applicant. Another caveat is that lenders generally have more information about a prospective borrower than was provided in this study's questionnaire. A third limitation is that the cell sample sizes were relatively small, ranging from 15 to 20 loan officers. Statistical power would have been enhanced by having larger sample sizes in each cell. Another limitation is that decision consequences were not present in this study. Participants did not suffer personal financial losses nor were there financial losses for the bank resulting from making poor lending decisions. Future research should conduct experiments where compensation to participants are impacted by the outcomes of their lending decisions.

\section{References}

Albrecht, A.-G., Ones, D.S., Dilchert, S., Deller, J. and Paulus, F.M. (2018). Tolerance of Ambiguity: Relations with Expatriate Adjustment and Job Performance. Managing Expatriates: Success Factors in Private and Public Domains, Series on Population Studies 50. [Online] https://books.google.com/books?hl=en\&lr=\&id=eCRpDwAAQBAJ\&oi=fnd\&pg=PA71\&d $\mathrm{q}=$ albrecht+ones+dilchert+deller+paulus\&ots=xQ5JZDakcQ\&sig=K4NTj5eKHD4tLYri2QmCJyQMXI\# $\mathrm{v}=$ onepage\&q=albrecht\%20ones\%20dilchert\%20deller\%20paulus\&f=fal se.>[Date of access: 9.1.20]

Chong, V.K. (1998). Testing the Contingency "Fit" Between Management Accounting Systems and Managerial Performance: A Research Note on the Moderating Role of Tolerance for Ambiguity, The British Accounting Review, 30(4): 331-342.

Church, B.K. and Schneider, A. (2016). The Impact of Section 302 and 404 (B) Internal Control Disclosures on Prospective Investors' Judgments and Decisions: An Experimental Study, International Journal of Auditing, 20(2): 175-185.

Costello, A.M. and Wittenberg-Moerman, R. (2011). The Impact of Financial Reporting Quality on Debt Contracting: Evidence from Internal Control Weakness Reports, Journal of Accounting Research, 49(1): 97-136. 
Dermer, J.D. (1973). Cognitive Characteristics and the Perceived Importance of Information, The Accounting Review, 48(3): 511-519.

Dhaliwal, D., Hogan, C., Trezevant, R. and Wilkins, M. (2011). Internal Control Disclosures, Monitoring, and the Cost of Debt, The Accounting Review, 86(4): 1131-1156.

Earley, C.E., Hoffman, V.B., and Joe, J.R. (2008). Reducing Management's Influence on Auditors' Judgments: An Experimental Investigation of SOX 404 Assessments, The Accounting Review, 83(6): 1461-1485.

Faircloth, A.W. and Ricchiute, D.N. (1981). Ambiguity Intolerance and Financial Reporting Alternatives, Accounting, Organizations and Society, 6(1): .53-67.

Furnham, A. and Marks, J. (2013). Tolerance of Ambiguity: A Review of the Recent Literature, Psychology, 4(09): 717-728.

Furnham, A. and Ribchester, T. (1995). Tolerance of Ambiguity: A Review of the Concept, Its Measurement and Applications, Current Psychology, 14(3): 179-199.

Gul, F.A. (1984). The Joint and Moderating Role of Personality and Cognitive Style on Decision Making, The Accounting Review, 59(2): 264-277.

Gul, F.A. (1986). Tolerance for Ambiguity, Auditors' Opinions and Their Effects on Decision Making, Accounting and Business Research, 16(62): 99-105.

Hammersley, J.S., Myers, L.A. and Shakespeare, C. (2008). Market Reactions to the Disclosure of Internal Control Weaknesses and to the Characteristics of Those Weaknesses Under Section 302 of the Sarbanes Oxley Act of 2002, Review of Accounting Studies, 13(1): 141-165.

Hogan, C.E. and Wilkins, M.S. (2008). Evidence on the Audit Risk Model: Do Auditors Increase Audit Fees in the Presence of Internal Control Deficiencies?, Contemporary Accounting Research, 25(1): 219-242.

Jiang, W., Rupley, K.H. and Wu, J. (2010). Internal Control Deficiencies and the Issuance of Going Concern Opinions, Research in Accounting Regulation, 22(1): 40-46.

Kim, Y. and Park, M.S. (2009). Market Uncertainty and Disclosure of Internal Control Deficiencies Under the Sarbanes-Oxley Act, Journal of Accounting and Public Policy, 28(5): 419-445.

Kim, J.B., Song, B.Y. and Zhang, L. (2011). Internal Control Weakness and Bank Loan Contracting: Evidence from SOX Section 404 Disclosures, The Accounting Review, 86(4): 1157-1188.

Li, Y., Yu, J., Zhang, Z. and Zheng, S.X. (2016). The Effect of Internal Control Weakness on Firm Valuation: Evidence from SOX Section 404 Disclosures, Finance Research Letters, 17: 17-24.

MacDonald Jr, A.P. (1970). Revised Scale for Ambiguity Tolerance: Reliability and Validity, Psychological Reports, 26: 791-798. 
McGhee, W., Shields, M.D. and Birnberg, J.G. (1978). The Effects of Personality on a Subject's Information Processing, The Accounting Review, 53(3): 681-697.

Norton, R.W. (1975). Measurement of Ambiguity Tolerance, Journal of Personality Assessment, 39(6): 607-619.

Oliver, J. and Flamholtz, E. (1978). Human Resource Replacement Cost Numbers, Cognitive Information Processing, and Personnel Decisions: A Laboratory Experiment, Journal of Business Finance \& Accounting, 5(2): 137-157.

Pincus, K.V. (1990). Auditor Individual-Differences and Fairness of Presentation Judgments, Auditing: A Journal of Practice \& Theory, 9(3): 150-166.

Schneider, A. (2018). Financial Expertise on Audit Committees of Loan Applicants: A Research Note to Test the Effects on Lending Decisions, Accounting and Business Research, 48(2): 225235.

Schneider, A. and Church, B.K. (2008). The Effect of Auditors' Internal Control Opinions on Loan Decisions, Journal of Accounting and Public Policy, 27(1): 1-18.

Tsui, J. (1993). Tolerance for Ambiguity, Uncertainty Audit Qualifications and Bankers' Perceptions, Psychological Reports, 72(3): 915-919.

Vaassen, E.H., Baker, C.R. and Hayes, R.S. (1993). Cognitive Styles of Experienced Auditors in the Netherlands, The British Accounting Review, 25(4): 367-382.

Weisbrod, E. (2009). The Role of Affect and Tolerance of Ambiguity in Ethical Decision Making, Advances in Accounting, 25(1): 57-63.

Wright, M.E. and Davidson, R.A. (2000). The Effect of Auditor Attestation and Tolerance for Ambiguity on Commercial Lending Decisions, Auditing: A Journal of Practice $\mathcal{E}$ Theory, 19(2): 67-81. 